\title{
Role of aspirin discontinuation in recurrence of ischemic cerebrovascular stroke
}

\author{
Mohamed Negm ${ }^{*}$ and Reda Abd El-Razek
}

\begin{abstract}
Background: Discontinuation of aspirin was suggested to be a risk factor for recurrent ischemic stroke; however, it was underestimated by most physicians.

Objectives: Study the effect of aspirin discontinuation in recurrence of ischemic cerebrovascular stroke.

Patients and methods: This is a descriptive case-control study, including 104 patients with recurrent ischemic stroke and 104 controls. Both sexes were included with age over 18 years. The following information was collected: history of aspirin discontinuation and cause and time of discontinuation. Investigations included brain CT or brain MRI for all patients, and the site of infarction was classified according to the Oxford classification.

Results: We found that $51 \%$ of patients discontinue aspirin compared to $28.8 \%$ of the control group. Nearly half of the patients (25/53) discontinue aspirin for 8-30 days before a stroke. Very high-risk patients were associated with stroke in 8-30 days of discontinuation, high-risk patients were associated with stroke in 181-365 days of discontinuation while moderate-risk patients were associated with stroke in 31-180 days of discontinuation.

Conclusion: Discontinuation of aspirin especially for a period of 8-30 days could increase the risk of recurrent ischemic stroke in patients with very high-risk and high-risk factors. Physicians need to educate patients about the importance of adherence of aspirin therapy.
\end{abstract}

Keywords: Aspirin, Discontinuation, Recurrent stroke, Ischemic stroke

\section{Introduction}

The incidence of ischemic cerebrovascular strokes and transient ischemic attacks was about 5.0 per 1000 person per year [1]. The recurrence rate of ischemic stroke was reported to be $40 \%$ after 5 years of follow-up [2]. In other studies, the frequency of prior ischemic stroke in patients with acute ischemic stroke is about $11-25 \%$. [3-7]

Aspirin is the cornerstone of secondary stroke prevention [8]. It can cause a reduction in ischemic stroke of about 25\% in high-risk patients [9]. Many situations are associated with the discontinuation of aspirin: before surgical interventions, hemorrhagic disorders, interactions with other drugs, the patient's negligence, dementia, and drug intolerance. Because of the extended use of aspirin and the urge of its stopping for the above mentioned reasons, the occurrence of a prothrombotic effect after the discontinuation of aspirin therapy may play an important role in recurrence of ischemic cerebrovascular disease [1].

* Correspondence: Mohnegm2@yahoo.com Department of neuropsychiatry, Faculty of Medicine, Suez Canal University, Ismailia, Egypt
The rate of ischemic stroke after stop of aspirin has not been clearly studied [10]. Discontinuation of aspirin agents is a risk factor for stroke; however, it is underestimated by most physicians [11].

The cause of the increased rate of stroke and transient ischemic attack (TIA) after stopping aspirin is a rebound prothrombotic effect, recurrence can occur 8-21 days after stopping aspirin use [11]. Stopping aspirin can result in a rebound effect involving platelet formation and aggregation [1].

The aim of this work was to study the effect of aspirin discontinuation in recurrence of ischemic cerebrovascular stroke.

\section{Patients and methods}

This is a descriptive case-control study, including 104 patients with recurrent ischemic stroke admitted to the inpatient neurology department of Suez Canal University Hospital, Egypt, and 104 controls that have a single old stroke attack that matched for age and sex. Both sexes

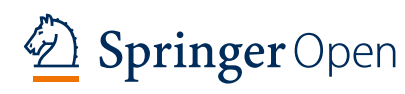

(c) The Author(s). 2019 Open Access This article is distributed under the terms of the Creative Commons Attribution 4.0 International License (http://creativecommons.org/licenses/by/4.0/), which permits unrestricted use, distribution, and reproduction in any medium, provided you give appropriate credit to the original author(s) and the source, provide a link to the Creative Commons license, and indicate if changes were made. 
were included with age over 18 years. We excluded patients with hemorrhagic stroke, a cardiac cause of stroke, and a history of cancer and patients who use of another antiplatelet or anticoagulant.

The following information was collected: full neurological history, history of current aspirin (75-300 mg/day) discontinuation including cause of discontinuation (switch to other antiplatelet, noncompliance, side effects, over the counter use), time of discontinuation in days (0-7 8-30, $31-180$, and $>181$ ), history of other drug discontinuation, and history of non-steroidal anti-inflammatory drug (NSAID) use. Full neurological examination was done including assessment of stroke severity on admission by the National Institutes of Health Stroke Scale (NIHSS) according to the scale; strokes were classified to mild, moderate, and moderate to severe [12]. Risk factors for ischemic stroke were evaluated by stroke chart [13] (Table 1).

Investigations included brain CT (Siemens, Balance Somatom, single-slice instrument, Germany) or brain MRI (1.5 Tesla MR Imager, Achieva, Philips Medical Systems, Best, Netherlands) for all patients, and the site of infarction was classified according to the Oxford classification (total anterior circulation, partial anterior circulation, lacunar infarction, and posterior circulation).

\section{Statistical analysis}

Data were fed to the computer and analyzed using IBM SPSS software package version 20.0. (Armonk, NY, IBM Corp). The Kolmogorov-Smirnov, Shapiro, and D'agstino tests were used to verify the normality of distribution of variables. Comparisons between groups for categorical variables were assessed using chi-square test. Student $t$ test was used to compare two groups for normally distributed quantitative variables. Regression was used to detect the most independent/affecting factor for recurrence cases. Results were considered significant at an alpha level of 5\%.

\section{Ethical considerations}

An informed written consent was taken from each patient or family. All data or investigations obtained from every patient were confidential and were not used outside the study. All the cost of the investigations was afforded by the researcher. Participants have the right to withdraw from the study at any time without giving any reason and will be excluded from the study.

The study was approved from the ethical committee of the Faculty of Medicine, Suez Canal University, on July 18, 2017 (Research\# 3141).

\section{Results}

This study included 104 patients with recurrent ischemic stroke and 104 as control. In patients, males represent $65(62.5 \%)$, and females 39 (37.5\%) while in controls, males represent $64(61.5 \%)$, and females 40 (38.5\%). The mean age for patients was $64.2 \pm 7.9$ and for control was $64.3 \pm 7.3$; no significant statistical difference between both groups was found regarding sex and age. Risk factors of stroke showed no significant statistical difference between both groups (Table 2).

According to aspirin discontinuation, 51\% of patients discontinue aspirin compared to $28.8 \%$ of the control group with significant statistical difference between both groups. Cause of discontinuation showed no significant difference between both groups. According to time of discontinuation, no patients develop stroke when aspirin stopped for $0-7$ days and nearly half of the patients (25/ 53) discontinue aspirin for $8-30$ days before stroke with significant statistical difference between both groups (Table 3). Other drug discontinuation showed no significant difference between both groups; however, there was a significant difference between both groups according to history of NSAID use (Table 3).

Table 4 shows the relation between time of discontinuation and risk factors of stroke. very high-risk patients were associated with stroke in 8-30 days of discontinuation, high-risk patients were associated with stroke in 181-365 days of discontinuation while moderate-risk patients were associated with stroke in 31-180 days of discontinuation with significant statistical difference. In contrast, in the control, no significant difference exists between time of discontinuation and risk factors of stroke.

According to NIHSS score in patients, minor stroke was present in 19 (18.3\%), moderate stroke in 52 (50.0\%), and moderate to severe stroke in 33 (31.7\%). In patients who discontinue aspirin (53), minor stroke was present in 11 (20.8\%), moderate stroke in 17 (32.1\%), and moderate to severe stroke in 25 (47.2\%).

The Oxford classification of the site of stroke showed that in patients, the total anterior circulation infarct was present in 17 (16.3\%), partial anterior circulation infarct in 45 (43.3\%), lacunar infarct in $32(30.8 \%)$, and posterior circulation infarct in $10(9.6 \%)$ and in control 19 (18.3\%) 41 (39.4\%), 34 (32.7\%), and 10 (9.6\%), respectively, with no significant difference existing between both groups.

In patients who discontinue aspirin (53), total anterior circulation infarct was present in $13(24.5 \%)$, partial anterior circulation in $8(15.1 \%)$, lacunar infarct in 22 (41.5\%), and posterior circulation in 10 (18.9\%).

Table 5 showed the multivariate analysis logistic regression to detect the most independent/ affecting factor for recurrence cases, only aspirin discontinuation and history of NSAID use was significantly associated with stroke recurrence.

\section{Discussion}

We found that 53 (51\%) of recurrent stroke patients discontinue aspirin compared to $30(28.8 \%)$ of the control group with significant statistical difference between both 
Table 1 Chart for Risk Factors of Ischemic Stroke

\begin{tabular}{|c|c|c|c|c|}
\hline Risk Factors & 0 & 1 & 2 & 3 \\
\hline Smoking & Never smoked & $\begin{array}{l}\text { Quit after smoking for less } \\
\text { than } 5 \text { years }\end{array}$ & Current smoker less than 20/day & $\begin{array}{l}\text { Current smoker more than } \\
\text { 20/day }\end{array}$ \\
\hline Exercise & $\begin{array}{l}1 \mathrm{~h} \text { strenuous activity at least } 3 \\
\text { times per week }\end{array}$ & $\begin{array}{l}\text { Very active once or twice } \\
\text { a week }\end{array}$ & $\begin{array}{l}\text { Moderately active once or twice } \\
\text { a week }\end{array}$ & Very little physical activity \\
\hline Diabetes & None known & N/a & Family history & Diabetic \\
\hline $\begin{array}{l}\text { Blood } \\
\text { pressure }\end{array}$ & Normal & Mild high blood pressure & Moderate high blood pressure & Severe high blood pressure \\
\hline Age & $0-44$ & $45-64$ & $65-74$ & $75+$ \\
\hline $\begin{array}{l}\text { Alcohol } \\
\text { (male) }\end{array}$ & 0-4 standard drinks/week & Up to 4 drinks/day & $\begin{array}{l}\text { More than } 4 \text { drinks a day } 2 \text { or } \\
\text { more days a week }\end{array}$ & $\begin{array}{l}\text { More than } 6 \text { drinks, } 4 \text { or more } \\
\text { days a week }\end{array}$ \\
\hline $\begin{array}{l}\text { Alcohol } \\
\text { (female) }\end{array}$ & 0-2 standard drinks a week & Up to 2 drinks a day & $\begin{array}{l}\text { More than two drinks a day, } 2 \text { or } \\
\text { more days a week }\end{array}$ & $\begin{array}{l}\text { More than } 4 \text { drinks, } 4 \text { or more } \\
\text { days a week }\end{array}$ \\
\hline Weight & About average for height & Slightly overweight & Moderately overweight & Obese \\
\hline $\begin{array}{l}\text { Family } \\
\text { history }\end{array}$ & No strokes known & $\begin{array}{l}\text { A relative has had a } \\
\text { stroke }\end{array}$ & $\begin{array}{l}\text { A relative has had a stroke while } \\
\text { younger than } 65\end{array}$ & $\begin{array}{l}\text { Several relatives have suffered } \\
\text { from stroke }\end{array}$ \\
\hline Cholesterol & Below average & Average & Moderately raised & Severely raised \\
\hline
\end{tabular}

0-4 very low risk, 5-9 moderate risk, 10-13 high risk, 14+ very high risk

groups. Among patients who stopped aspirin, we found that no stroke occurs when aspirin stopped for 0-7 days, $25(48 \%)$ in period of 8-30 days, $13(24 \%)$ in period of $31-180$ days and $15(28 \%)$ in period of $>181$ days.

This agrees with Maulaz and colleagues [11] who claimed that the stroke can occur 8-21 days after stopping aspirin use and withholding aspirin for $5-7$ days is risk-free. Also, Sibon and Orgogozo [14] mentioned that 4.49\% of strokes were related to a recent aspirin discontinuation, but all cases developed between 6 and 10 days after discontinuation $(p<0.0001)$. Also, Weimar and colleagues [15] reported that stroke was associated with absolute excess risk of $0.77 \%$ within 30 days after discontinuation of aspirine + extended-release dipyridamole.
On other hand, Rodriguez and colleagues [1] reported that $10.0 \%$ of patients had discontinued recently (31-180 days), and $4.3 \%$ had discontinued in the past (181-365 days) and that the risk was higher in patients who had stopped use 1 to 15 days before the event.

These findings can be explained by rebound effect after aspirin withdrawal [16]. The cause of the increased rate of stroke after stop aspirin is a rebound prothrombotic effect [11]. Halting of aspirin results in a rebound effect involving platelet formation and aggregation, thus the increase in events immediately after aspirin is discontinued [1]. Stimulatory effect on platelet basal production of arachidonic acid metabolites occurs when measured 3 weeks after stopping aspirin therapy and suggested the induction

Table 2 Demographic data and Risk factors of stroke in cases and control

\begin{tabular}{|c|c|c|c|c|}
\hline & Cases $(n=104)$ & Control $(n=104)$ & Test of sig. & $p$ \\
\hline \multicolumn{5}{|l|}{ Sex } \\
\hline Male & $65(62.5 \%)$ & $64(61.5 \%)$ & $x^{2}=0.020$ & 0.886 \\
\hline Female & 39 (37.5\%) & $40(38.5 \%)$ & & \\
\hline Age (years) & $64.2 \pm 7.9$ & $64.3 \pm 7.3$ & $t=0.037$ & 0.971 \\
\hline Smoking & $59(56.7 \%)$ & $59(56.7 \%)$ & $x^{2}=0.0$ & 1.000 \\
\hline Hypertension & $8(7.7 \%)$ & $9(8.7 \%)$ & $x^{2}=0.064$ & 0.800 \\
\hline Diabetes mellitus & $16(15.4 \%)$ & 17 (16.3\%) & $x^{2}=0.036$ & 0.849 \\
\hline Statin discontinuation & $23(22.1 \%)$ & $23(22.1 \%)$ & $x^{2}=0.0$ & 1.000 \\
\hline \multicolumn{5}{|l|}{ Risk factors of stroke } \\
\hline Very low risk & $0(0 \%)$ & $0(0 \%)$ & $x^{2}=0.035$ & 0.983 \\
\hline Moderate risk & $43(41.3 \%)$ & $42(40.4 \%)$ & & \\
\hline High risk & $40(38.5 \%)$ & 40 (38.5\%) & & \\
\hline Very high risk & $21(20.2 \%)$ & $22(21.2 \%)$ & & \\
\hline
\end{tabular}

Data were described using number and percent, in mean \pm SD or in median (Min. - Max)

*Statistically significant at $p \leq 0.05$ 
Table 3 Comparison between the two studied groups according to aspirin use

\begin{tabular}{|c|c|c|c|c|}
\hline & Cases $(n=104)$ & Control $(n=104)$ & Test of sig. & $p$ \\
\hline Aspirin Discontinuation & $53(51.0 \%)$ & $30(28.8 \%)$ & $x^{2}=9.100^{*}$ & $0.003^{*}$ \\
\hline \multicolumn{5}{|l|}{ Cause of discontinuation } \\
\hline Switch to other antiplatelet & $9(8.7 \%)$ & $5(4.8 \%)$ & $x^{2}=0.006$ & 0.997 \\
\hline Non compliance & $32(30.8 \%)$ & $18(17.3 \%)$ & & \\
\hline Side effects & $12(11.5 \%)$ & $7(6.7 \%)$ & & \\
\hline Over the counter use & $0(0 \%)$ & $0(0 \%)$ & & \\
\hline \multicolumn{5}{|l|}{ Time of discontinuation (days) } \\
\hline $0-7$ & $0(0 \%)$ & $6(5.8 \%)$ & $x^{2}=16.249^{*}$ & $<0.001^{*}$ \\
\hline $8-30$ & $25(24 \%)$ & $18(17.3 \%)$ & & \\
\hline $31-180$ & $13(12.5 \%)$ & $4(3.8 \%)$ & & \\
\hline$>181$ & $15(14.4 \%)$ & $2(1.9 \%)$ & & \\
\hline \multicolumn{5}{|l|}{ Other drug discontinuation } \\
\hline No & $77(74 \%)$ & $66(63.5 \%)$ & $x^{2}=3.156$ & 0.237 \\
\hline Statins & $25(24 \%)$ & $33(31.7 \%)$ & & \\
\hline Antihypertensives & $2(1.9 \%)$ & $5(4.8 \%)$ & & \\
\hline History of NSAID use & $2(1.9 \%)$ & $13(12.5 \%)$ & $x^{2}=8.694^{*}$ & $0.003^{*}$ \\
\hline
\end{tabular}

Data were described using number and percent, in mean \pm SD or in median (Min.-Max.)

*Statistically significant at $p \leq 0.05$

of a new platelet population with higher cyclooxygenase activity [17].

We found no significant difference between both groups in relation to stopping statins or antihypertensives; however, there was significant statistical difference between both groups according to history of NSAID use, as 13 (12.5\%) of control were found to use NSAIDs; on other hand, only $2(1.9 \%)$ of patients use it, which may suggest a protective role of NSAIDs.

Support this finding Rodriguez and colleagues [1], who mentioned that there was no observed increase in the risk of stroke/TIA among the subgroup of patients who concomitantly took aspirin and non-cyclooxygenase-2 (COX2) non-steroidal anti-inflammatory drugs (NSAIDs), despite a possible interference of NSAIDs with aspirin's antiplatelet activity.
We found that non-compliance was the major cause of discontinuation in our patients which occur in $32 \mathrm{pa}-$ tients out of 53 patients who stop aspirin. This comes in accordance with Rodriguez and colleagues [1] who claimed that patient nonadherence was the major cause for discontinuation of aspirin therapy which in turn leads to increased stroke risk. On the other hand, Maulaz and colleagues [11] mentioned that the main reasons for stop aspirin were surgery, decision of the treating physician's that therapy had no clear clinical benefit, bleeding, negligence, and dementia.

We found that patients who stop aspirin for 8-30 days were associated with a very high-risk score, patients who stop aspirin for 31-180 days were associated with a moderate-risk score, and patients who stop aspirin for 181-365 days were associated with a high-risk score with

Table 4 Comparison of time of aspirin discontinuation and different grades of risk factors score in both groups

\begin{tabular}{|c|c|c|c|c|c|c|}
\hline \multirow{2}{*}{$\begin{array}{l}\text { Risk factors of } \\
\text { stroke }\end{array}$} & \multicolumn{4}{|c|}{ Time of discontinuation (days) } & \multirow[t]{2}{*}{$x^{2}$} & \multirow[t]{2}{*}{$p$} \\
\hline & $0-7$ & $8-30$ & $31-180$ & $181-365$ & & \\
\hline Cases & $(n=0)$ & $(n=25)$ & $(n=13)$ & $(n=15)$ & & \\
\hline Moderate risk & - & $4(16 \%)$ & $7(53.8 \%)$ & $0(0 \%)$ & $19.110^{*}$ & $0.001^{*}$ \\
\hline High risk & - & $10(40 \%)$ & $2(15.4 \%)$ & $13(86.7 \%)$ & & \\
\hline Very high risk & - & $11(44 \%)$ & $4(30.8 \%)$ & $2(13.3 \%)$ & & \\
\hline Control & $(n=6)$ & $(n=18)$ & $(n=4)$ & $(n=2)$ & & \\
\hline Moderate risk & $3(50 \%)$ & $4(22.2 \%)$ & $3(75 \%)$ & $0(0 \%)$ & 6.254 & 0.389 \\
\hline High risk & $2(33.3 \%)$ & $8(44.4 \%)$ & $0(0 \%)$ & $1(50 \%)$ & & \\
\hline Very high risk & $1(16.7 \%)$ & $6(33.3 \%)$ & $1(25 \%)$ & $1(50 \%)$ & & \\
\hline
\end{tabular}

Data were described using number and percent

*Statistically significant at $p \leq 0.05$ 
Table 5 Univariate and multivariate analysis to detect the most independent/ affecting factor for recurrence cases

\begin{tabular}{|c|c|c|c|c|}
\hline & \multicolumn{2}{|l|}{ Univariate } & \multicolumn{2}{|l|}{${ }^{\#}$ Multivariate } \\
\hline & OR $(95 \%$ C.I) & $\mathrm{p}$ & OR $(95 \%$ C.I) & $\mathrm{p}$ \\
\hline Sex (female) & $0.960(0.548-1.681)$ & 0.886 & - & - \\
\hline Age (years) & $0.999(0.964-1.036)$ & 0.971 & - & - \\
\hline Smoking & $1.000(0.578-1.731)$ & 1.000 & - & - \\
\hline Hypertension & $0.880(0.326-2.376)$ & 0.800 & - & - \\
\hline Diabetes mellitus & $0.930(0.442-1.958)$ & 0.849 & - & - \\
\hline Statin discontinuation & $1.000(0.519-1.925)$ & 1.000 & - & - \\
\hline Aspirin Discontinuation & $2.563(1.446-4.544)$ & $0.001^{*}$ & $2.331(1.303-4.171)$ & $0.004^{*}$ \\
\hline History of NSAID use & $0.137(0.030-0.625)$ & $0.010^{*}$ & $0.168(0.036-0.777)$ & $0.022^{*}$ \\
\hline
\end{tabular}

$O R$ odd's ratio, $C l$ confidence interval,

*Statistically significant at $p \leq 0.05$

\#All variables with $p<0.05$ was included in the multivariate

significant statistical difference. Maulaz and colleagues [11] reported that discontinuation of aspirin is a significant risk factor for a cerebral stroke in the 4 weeks after aspirin discontinuation and the mean interval between treatment withdrawal and stroke was 9.5 days. Recent discontinuers (31-180) had a significant greater risk (40\%) for ischemic stroke, and past discontinuers $(>180)$ had a non-significant greater risk (25\%) [1].

In our patients, $50 \%(N=52 / 104)$ showed a moderate NIHSS score. In patients who discontinue aspirin, $47.2 \%$ $(N=25 / 53)$ showed severe NIH score. These findings indicate that more sever stroke may follow aspirin discontinuation and no previous data to our knowledge deal with this point.

The Oxford classification showed that partial anterior circulation infarct was present in $45(43.3 \%)$ of patients and 41 (39.4\%) in the control group. This comes in accordance with Mead and colleagues [18], who found that partial anterior circulation infarcts were present in $34 \%$ of stroke patients. Also, Bamford and colleagues [19] reported that partial anterior circulation infarcts were associated with the highest risk of early (within 3 months) recurrence of stroke. The suspected embolic origin of partial anterior circulation and our exclusion of cardiac cause may refer to undiagnosed cardiac patients as paroxysmal AF.

In patients who discontinue aspirin, lacunar infarct was present in $22(41.5 \%)$ according to the Oxford classification. On the other hand, Maulaz and colleagues [11] reported that cardioembolic stroke was the commonest type of stroke associated with aspirin discontinuation. This contradictory may be explained by the different methodology and our exclusion of diagnosed cardiac patients.

Multivariate analysis logistic regression showed that aspirin discontinuation was an independent factor for recurrent stroke; this comes in accordance with previous studies $[1,11]$.

Limitations of the study include the low number of patients that were included, the need for more investigation for risk factors, and data were limited as to the etiology of the prior strokes. Other limitations were related to the case-control design as differential errors are hard to avoid because the data for the patients and controls is collected under different circumstances. However, both groups were comparable. Also the frequency of aspirin discontinuation may have been underestimated because patients may not report treatment compliance correctly because of confusion, aphasia, and deterioration of consciousness that may occur in acute stroke. Also, patients with nonadherence or dementia may not report drug discontinuation, and the delay between treatment cessation and cerebral infarct may be underestimated for the same reasons.

One of the strengths of our study is the high frequency of MRI investigations contributing to reliable stroke subtyping. The strength is not retrospective, studying many factors not included in most other studies like risk factors, NIH score, and oxford classification.

In conclusion, the discontinuation of aspirin especially for a period of 8-30 days could increase the risk of recurrent ischemic stroke in patients with high and very high-risk factors and we should be aware of the complications of stopping aspirin use. Not to use aspirin at all may be better than to stop it after use. Very high-risk patients must be advised not to stop aspirin and if a must, not more than 7 days. Physicians need to educate patients about the importance of adherence of aspirin therapy.

\section{Abbreviations \\ AF: Atrial fibrillation; COX2: Cyclooxygenase-2; NIHSS: National Institutes of Health Stroke Scale; NSAIDs: Non-steroidal anti-inflammatory drugs; TIA: Transient ischemic attack}

\section{Acknowledgements}

Not applicable

Funding

Not applicable 


\section{Availability of data and materials}

The paper is a part of thesis conducted inFaculty of Medicine, Suez Canal University and approved by its ethical committee. The data can be publiclyavailable at the Faculty of Medicine, Suez Canal University.

\section{Authors' contributions}

MN contributed to the idea of the research, design of the study, and prepared the paper's final revision. RA to the practical works involved in the design of the study and performed the statistical analysis. All authors read and approved the final manuscript.

\section{Ethics approval and consent to participate}

The study was approved from ethical committee Faculty of Medicine, Suez Canal University on 19/7/2017 (Research\# 3141).

An informed written consent was taken from each patientor family. All data or investigations obtained from every patient were confidential and were not used outside the study. The patients have rights to withdraw from the study at any time without giving any reason. All the cost of the investigations was afforded by the researcher. Participants have the right to withdraw from the study at any time without giving any reason and will be excluded from the study.

\section{Consent for publication}

Not applicable

\section{Competing interests}

The authors declare that they have no competing interests.

\section{Publisher's Note}

Springer Nature remains neutral with regard to jurisdictional claims in published maps and institutional affiliations.

Received: 16 September 2018 Accepted: 5 February 2019

Published online: 13 February 2019

\section{References}

1. Rodriguez LAG, Soriano LC, Hill C, Johansson S. Increased risk for stroke after discontinuation of acetylsalicylic acid: a UK primary care study. Neurology. 2011;76:740-6.

2. Eriksson SE, Olsson JE. Survival and recurrent strokes in patients with different subtypes of stroke: a fourteen year follow-up study. Cerebrovasc Dis. 2001;12:171-80.

3. Weimar C, Ziegler A, Konig IR, Diener HC. Predicting functional outcome and survival after acute ischemic stroke. J Neurol. 2002;249:888-95.

4. Indredavik B, Bakke F, Solberg R, Rokseth R, Haaheim LL, Holme I. Benefit of a stroke unit: a randomized controlled trial. Stroke. 1991;22:1026-31.

5. Terent A, Asplund K, Farahmand B, Henriksson KM, Norrving B, Stegmayr B et al. Stroke unit care revisited: who benefits the most? A cohort study of 105,043 patients in Riks-Stroke, the Swedish Stroke Register. J Neurol Neurosurg Psychiatry. 2009;80:881-7.

6. Grau AJ, Weimar C, Buggle F, Heinrich A, Goertler M, Neumaier S, et al. Risk factors, outcome, and treatment in subtypes of ischemic stroke: the German stroke data bank. Stroke. 2001;32:2559-66.

7. Inzitari D, Di Carlo A, Pracucci G, Lamassa M, Vanni P, Romanelli M, et al. Incidence and determinants of post stroke dementia as defined by an informant interview method in a hospital-based stroke registry. Stroke. 1998; 29:2087-93.

8. Amrein PC, Ellman L, Harris WH. Aspirin-induced prolongation of the bleeding time and perioperative blood loss. JAMA. 1981;245:1825-8.

9. Antithrombotic Trialists' Collaboration. Collaborative meta-analysis of randomised trials of antiplatelet therapy for prevention of death, myocardial infarction, and stroke in high risk patients. BMJ. 2002;32:471-86.

10. Cahill RA, McGreal GT, Crowe BH, Ryan DA, Manning BJ, Cahill MR, et al. Duration of increased bleeding tendency after cessation of aspirin therapy. J Am Coll Surg. 2005;200:564-73.

11. Maulaz AB, Bezerra DC, Michel P, Bogousslavsky J. Effect of discontinuing aspirin therapy on the risk of brain ischemic stroke. Arch Neurol. 2005;62: $1217-20$.

12. Hage $\mathrm{V}$. The NIH stroke scale: a window into neurological status. Nurs Spect. 2011;24(15):44-9.
13. Brain foundation. Stroke risk self-assessment chart: Available from https:// brainfoundation.org.au/disorders/stroke/

14. Sibon I, Orgogozo JM. Antiplatelet drug discontinuation is a risk factor for ischemic stroke. Neurology. 2004;62(7):1187-9.

15. Weimar C, Cotton D, Sha N, Sacco RL, Bath PM, Weber R, et al. Discontinuation of antiplatelet study medication and risk of recurrent stroke and cardiovascular events: results from the PRoFESS study. Cerebrovasc Dis. 2013;35(6):538-43.

16. Bachman DS. Discontinuing chronic aspirin therapy: another risk factor for stroke? Ann Neurol. 2002;51:137-8.

17. Beving H, Eksborg S, Malmgren RS, Nordlander R, Ryden L, Olsson P. Interindividual variations of the effect of low dose aspirin regime on platelet cyclooxygenase activity. Thromb Res. 1994;74(1):39-51.

18. Mead GE, Lewis SC, Wardlaw JM, Dennis MS, Warlow CP. How well does the Oxfordshire Community Stroke Project classification predict the site and size of the infarct on brain imaging? J Neurol Neurosurg Psychiatry. 2000;68(5): 558-62.

19. Bamford J, Sandercock P, Dennis M, Burn J, Warlow C. Classification and natural history of clinically identifiable subtypes of cerebral infarction. Lancet. 1991;337:1521-6.

\section{Submit your manuscript to a SpringerOpen ${ }^{\circ}$ journal and benefit from:}

- Convenient online submission

- Rigorous peer review

- Open access: articles freely available online

High visibility within the field

- Retaining the copyright to your article

Submit your next manuscript at $\boldsymbol{\nabla}$ springeropen.com 